contact the suction of the electric motor may prove of great danger to the eye.

It is difficult for the surgeon to keep his hand steady while engaging the lens, since he must at the same time exert pressure with his finger on the trigger which puts him into communication with the vacuum. The same inconvenience is seen in the syringe vacuum apparatus of Arruga and Lijo Paoia.

Further the capacity of the syringe in this instrument was only 5 c.c., which does not seem to produce a strong enough vacuum and the frequency with which the lens slips off the cup can be put down to the feeble suction. We have seen Arruga recharge the syringe several times during the same operation.

For this reason we have adopted a syringe of 20 c.c. which can produce different degrees of vacuum between 5 and 20 c.c.

With a mature cataract and a feeble zonule in a patient of 60 , 5 c.c. of vacuum is enough to extract the lens. This is equivalent to a suction of $30 \mathrm{~mm}$. $\mathrm{Hg}$ while 15 c.c. equals $70 \mathrm{~mm}$. $\mathrm{Hg}$.

In certain patients, particularly those under 50 and with unripe cataracts the zonule is more resistant and a 10 c.c. vacuum is required to luxate the lens without having to reapply the cup several times while rupturing the zonule. 10 c.c. of vacuum is enough to remove the lens in most cases.

\title{
WHITE OAK HOSPITAL, 1933-37
}

\section{The following report on White Oak Hospital has been submitted by Mr. Arnold Sorsby, visiting Ophthalmologist to the Hospital}

The considerable administrative changes that have occurred at White Oak Hospital during the past two-and-a-half years make a comparative review of the work of the past five years desirable. The subjoined table gives the admissions for 1933-37, set out in the main groups of affections treated.

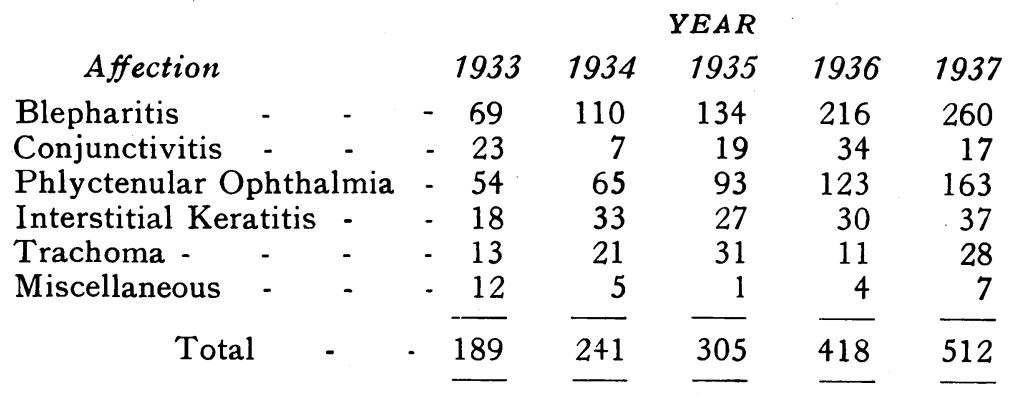


An analysis has been made of the admissions in 1933 and 1936 as regards the duration of treatment of individual cases. Excluding cases whose treatment was not completed (owing to the children being demanded out by their parents and other reasons) the subjoined table shows the length of treatment for the more important groups treated at the hospital.

\begin{tabular}{|c|c|c|c|c|c|c|c|c|c|c|}
\hline $\begin{array}{l}\text { Stay at Hospital } \\
\text { in Months }\end{array}$ & \multicolumn{2}{|c|}{ Blepharitis } & \multicolumn{2}{|c|}{ Con junctivitis } & \multicolumn{2}{|c|}{$\begin{array}{l}\text { Phlyctenular } \\
\text { Ophthalmia }\end{array}$} & \multicolumn{2}{|c|}{ Trachoma } & \multicolumn{2}{|c|}{$\begin{array}{c}\text { Interstitial } \\
\text { Keratitis }\end{array}$} \\
\hline & 1933 & 1936 & 1933 & 1936 & 1933 & 1936 & 1933 & 1936 & 1933 & 1936 \\
\hline $0-3$ & 6 & 46 & 9 & 8 & 24 & 11 & 1 & 1 & - & 2 \\
\hline $4-6$ & 5 & 84 & 3 & 12 & 9 & 33 & 2 & - & 4 & 5 \\
\hline $7-9$ & 3 & 28 & 5 & 4 & 5 & 41 & - & 4 & 2 & 7 \\
\hline $10-12$ & 8 & 7 & 1 & - & 2 & 8 & 1 & 1 & 2 & 7 \\
\hline $13-18$ & 8 & 1 & - & - & 2 & 1 & 3 & 1 & 4 & 2 \\
\hline $19-24$ & 7 & - & - & - & 0 & - & 0 & - & 2 & - \\
\hline Over 25 & 9 & - & 2 & - & 3 & - & 2 & - & 1 & - \\
\hline \multirow{2}{*}{$\begin{array}{l}\text { Still under } \\
\text { treatment }\end{array}$} & - & 7 & - & - & - & 4 & - & 3 & - & 4 \\
\hline & 46 & 173 & 20 & 24 & 45 & 98 & 9 & 10 & 15 & 27 \\
\hline
\end{tabular}

It will be seen that in 1933 of 46 cases of blepharitis fully treated, 11 or 24 per cent. were discharged within six months, whilst 15 or 32.6 per cent. required treatment for a period of one to two years and 9 or 19.5 per cent. for over two years. The figures for 1936 are a marked contrast. Of 173 no less than 130 or $75 \cdot 1$ per cent. were discharged within six months (46 cases or 26 per cent. being discharged within three months), whilst only one case took more than a year to cure, though to this must be added seven cases admitted in 1936 and still under treatment at the time of writing (December, 1937), making a percentage of 4.7 per cent. for cases requiring treatment for more than a year.

A further point of interest in this connection is the cases demanded out. In 1933 with a total of 189 admissions 41 were demanded, some of these cases belonging to the admissions of earlier years. Of these 41 , no less than 23 were blepharitis cases, and 11 of these had been in hospital for periods ranging between 12 and 24 months, and three for 11 months. With 418 admissions in 1936, 64 children were demanded out, 38 of whom were cases of blepharitis. Of these 38 cases, 12 had been in hospital for not more than 1 month, 19 one to 3 months, six for 4 to 6 months and one for 7 months. 
The figures for phlyctenular ophthalmia indicate a longer stay in 1936 than 1933. Of 45 cases treated in 1933,24 or 53.3 per cent. were discharged within 3 months and nine or 20 per cent. within 6 months. In 1936 of 98 cases only 11 or 11.2 per cent. were discharged within 3 months, 33 cases or $33^{\circ} 6$ per cent. within 6 months and 41 cases or 41.9 per cent. stayed at the hospital for a period of 6 to 9 months.

The figures for chronic conjunctivitis, trachoma and interstitial keratitis are too small to warrant any detailed conclusion, but generally speaking they indicate a shortening of the duration of stay. The position is therefore that in the largest group of cases, that of blepharitis, 75 per cent. of cases in 1936 as against 24 per cent. in 1933 were discharged within 6 months, and whilst 52 per cent. required treatment for more than one year in 1933, only 47 per cent. were in that position in 1936 . The longer stay now given to phlyctenular ophthalmia cases was found desirable because of the recognition that these cases are potentially tuberculous. Prolongation of treatment in these cases is therefore essentially a prophylactic measure, and it would seem to have justified itself by the great diminution in the number of recurrences, as judged by the follow-up system introduced last year. Owing to the lack of a follow-up system previously, it is not possible to give comparative statistical data, but it is justifiable to assume that a diminution, in view of the fact that few recurrences are seen now, and the condition is notoriously one in which recurrences are an important and troublesome feature.

The favourable results obtained in the blepharitis groups is largely due to the introduction of treatment by antiseptic dyes instead of the time honoured methods. No small measure must also be attached to the special attention given to the general health of the children, particularly to the introduction of a richer diet. The change of diet is especially important in the satisfactory general condition of the phlyctenular group, where treatment has been essentially on general lines.

One administrative aspect deserves a special note. Whilst every precaution has always been taken at White Oak for the segregation of the infectious eye cases, children with chronic conjunctivitis were regarded as fit to mingle with others. In 1935, 78 such children were placed in a separate block of cottages and given separate classrooms of their own. As a result it was found that fewer of the other children developed acute conjunctivitis; in fact no cases of acute conjunctivitis have been observed during the past two years. The specialised attention that the group arrangement of chronic conjunctivitis cases allowed, soon brought the number of these cases down. By the beginning of 1937 it was possible to close the special block for this group of cases. Apart from the 
trachoma cases - and these are rigorously segregated from the other children-and the occasional admission of a case of acute conjunctivitis-such cases being isolated till free from infection-there are now no infectious cases at White Oak Hospital.

On the clinical side, the blepharitis problem has ceased to be a major issue, but the aetiology of the affection still eludes a clear appreciation. A promising enquiry is being conducted at the Hospital by Mr. E. J. Somerset, the present holder of the Royal Eye Hospital Research Scholarship, who is studying the significance of refractive errors in blepharitis. The ample clinical material at the Hospital allowed the determination of the nature of phlyctenular ophthalmia as already noted. A final report of this subject is being completed, the preliminary report having been published in 1936 . A considerable amount of work has been done on possible new treatments for trachoma and interstitial keratitis. It is hoped that a later report may be more definite on this aspect.

\section{ANNOTATION}

\section{The Mechanism of Headache}

An interesting Presidential Address, delivered before the Glasgow Northern Medical Society by Mr. J. E. Paterson, is published in the November issue of the Glasgow Medical Journal, and deals with some features of headache. Briefly the subject is discussed under the following headings:-experimental histamine headache; migraine; ophthalmoplegic migraine and aneurysm, and posttraumatic headaches. The author is surgeon to Stobhill Hospital and neurological surgeon to the Victoria Infirmary. He says that intra-cranial operations can readily be carried out under local anaesthesia. The bone and the brain are both insensitive; but certain parts of the dura and lepto-meninges, when stimulated, give rise to pain. It is noteworthy that such painful spots are invariably where the main vessels lie. His experiences in intra-cranial surgery lead him to the conclusion that the blood vessels of the dura and lepto-meninges conduct painful stimuli. The headache found in experiments with histamine seems to be connected in some way with the pronounced vaso-dilatation produced by the drug. Paterson agrees with the suggestion that "the headache results, not from the actual dilatation itself, but from painful stimuli from the vessel walls excited by their greatly increased amplitude of pulsation." A point stressed by the author is that "recurrent attacks of headache associated with ocular palsy nearly always, if not always, signify a leaking aneurysm of the Circle of Willis." 